\title{
A qualitative study of young Nigerian family physicians' views of their specialty
}

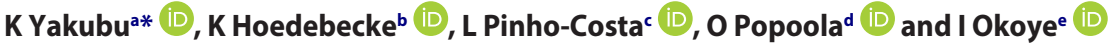 \\ ${ }^{a}$ Department of Family Medicine, University of Jos/Jos University Teaching Hospital, Jos, Nigeria \\ ${ }^{b}$ Yongsan Health Clinic, Seoul, South Korea \\ 'Fânzeres Family Health Unit, Gondomar, Portugal \\ ${ }^{d}$ Department of Family Medicine, Federal Staff Hospital, Abuja, Nigeria \\ ${ }^{e}$ Department of Family Medicine, University of Calabar Teaching Hospital, Calabar, Nigeria \\ *Corresponding author, email:danmasani1016@gmail.com
}

\begin{abstract}
Background: In Nigeria, the specialty of family medicine (FM) has endured its own share of identity crises. This study was aimed at generating hypotheses about what describes a practising family physician (FP) and the specialty, according to young Nigerian FPs. Methods: Using the online platform for young African FPs alongside text messages and emails from volunteer research assistants over an eight-week period (March 3 to April 30, 2015), a purposive sample of young Nigerian FPs were asked to describe their favourite aspect of FM in a single word/phrase. Responses were provided in English/individual's mother tongue. Translation of the words was performed by respondents and additional collaborators fluent in these languages. Thematic analysis using the grounded theory approach was performed.

Results: Twenty-four responses were received consisting of four themes: Scope, Family, Skills/Feelings/Values, and Professional Fulfilment. The resulting data portrayed the FP as one who possesses a unique skill-set, enjoys fulfilment in the profession, deals with undifferentiated diseases and is able to provide holistic care for patients (irrespective of age and gender) from a familycentred perspective. When compared with accepted domains of FM for Africa and Europe, roles of the FP in community-oriented care and primary care management were absent.

Conclusion: While this showcases the young Nigerian FPs' acceptance of their role in providing comprehensive primary care, it suggests a lesser acceptance of their role in community-oriented primary care as well as primary care management. This study provides a basis for future, quantitative research describing attitudes and competence in these areas.
\end{abstract}

Keywords: family practice, grounded theory, identity crisis, Nigeria, primary health care

\section{Introduction}

Since 1981 when the residency training in family medicine (FM) commenced in Nigeria, ${ }^{1,2}$ it has gained a great deal of recognition as the number of residency training centres has grown to about 120,3 reflecting a mixture of faith-based, general and tertiary hospitals located in either urban, semi-urban or rural communities. Despite this growth, the specialty has endured its own share of identity crises. Looking beyond this local setting to other developed countries, it is worth noting that this is not an uncommon issue. ${ }^{4}$ Locally the typical questions asked about FM seems to be centred on who a family physician (FP) is and what he/she does differently from other general medical practitioners (i.e. medical officers, internists, paediatricians etc.). Efforts aimed at answering these questions include the use of articles, seminars, symposia, activities of Young Doctor Movements (YDMs) like AfriWon Renaissance (the World Organisation of Family Doctors [WONCA] YDM for Africa) and even special events like the World Family Doctors day. ${ }^{5,6}$ Considering the growing number of FM training centres across Nigeria and incorporation of the subject into the undergraduate curriculum, one can say there has been an increased awareness of this unique specialty.? Nonetheless, these questions remain the same to date. Considering the growing interest in YDMs among FM Trainees and newly qualified FPs alike, ${ }^{8}$ studying what these young doctors like most about this specialty is one way of further addressing the questions of who a FP is and the unique characteristics of FM. This study was aimed at generating hypotheses on what describes a FP and the unique characteristics of the discipline specific for their setting, by asking young Nigerian FPs to identify what they like most about their specialty.

\section{Ethical considerations}

Ethical approval for this study was sought and obtained from the HREC of the University of Calabar, registration number NHREC/07/10/2012 and protocol assigned number UCTH/ HREC/33/483. Informed consent was sought and obtained from all participants who were also free to decline the use of their responses even after submission. No identification tag or number was stored.

\section{Methods}

As at the time of the study, there were about 120 FM residency training centres in Nigeria. ${ }^{3}$ Young Nigerian FPs on the AfriWon Renaissance Facebook forum numbered 110, of whom 20 indicated that they were certified FPs. The total number of young Nigerian FPs (i.e. resident doctors and certified FPs) was not known since a central registry was not available at the time of this study.

To help celebrate the 2015 edition of the World Family Doctor Day, a global initiative called One Word for Family Medicine (\#1WordforFamilyMedicine) was promoted by WONCA and YDMs from all seven WONCA regions. ${ }^{9}$ This study was a subproject in this initiative and a purposive sample of young FPs in Nigeria were asked to participate. Resident doctors and newly certified FPs (not more than five years post-qualification) were considered eligible. The survey questions were sent to them through the Facebook forum of AfriWon Renaissance, text messages and emails from volunteer research assistants in Nigeria. This began on March 3, 2015 and data collation continued till April 30, 2015. 
Even though the main aim of the study was to describe who an FP is and the unique characteristics of the discipline, participation in this study meant sharing one word or a short phrase, in English or mother tongue, that best described what the study participants liked most about FM. This indirect approach of answering a research question, known as lateral thinking, ${ }^{10,11}$ was chosen for its ability to elicit creative and unbiased responses. The study population for this study was chosen because they were still young, energetic and perhaps had not seen much of the wear and tear of the practice to develop a pessimistic outlook. This was considered an effective way of providing a country-specific picture of FM that the general and medical community can understand. Translation of the words was performed by the participants and additional collaborating doctors who could write in these languages and were also native speakers. Analysis was performed at the same time as data collection, consistent with the grounded theory approach. ${ }^{12}$ As each response was received, a label (code) that identified features relevant to answering the research question was written out. Comparing within responses, derivation of related units of meaning (themes) and writing down emerging theories was also done. This proceeded in a reiterative manner involving all five authors with inputs from the study participants till significant broader patterns of meaning (candidate themes) were identified. The latter were checked against the data-set to determine the scope and focus of each theme and whether they answered the research question. To ensure trustworthiness of the data, the final themes were compared with findings of similar studies from Italy, Argentina and Portugal. ${ }^{13-15}$ Member-checks, peer briefing, maintaining an audit trail and response validation were done as well. Analyses was done manually using Microsoft Word ${ }^{\circledR}$ (Microsoft Corp, Redmond, WA, USA).

\section{Results}

Twenty-four respondents participated in this survey; $71 \%(17 / 24)$ were males while $29 \%$ (7/24) were female. Some $83 \%(20 / 24)$ were FM trainees while $17 \%$ (4/24) were newly certified FPs, less than five years after qualification. While $75 \%(18 / 24)$ of the respondents were practising/training in a tertiary-based primary care setting, 17\% (4/24) were in a faith-based secondary care setting and $8 \%(2 / 24)$ in a general hospital. The mean (SD) age in years of the respondents was 35 (4). Apart from two responses in English, most of the respondents wrote in the following languages: Hausa, Eggon, Bachama, Taroh, Mupun, Tiv, Yoruba and Igbo; representing ethnic groups from northern, southwestern and south-eastern Nigeria. These results are graphically depicted in Figure 1.

Four themes were identified as follows:

(1) Scope, which was used in different languages including English and in different contexts as follows: 'Gbogbonise' (Yoruba word for all work), 'Kat' (Bachama for all), 'Namojir' (Mupun word for all categories of patients), 'Itoju ailera ti ko ko'rajopo si eya kan' (Yoruba phrase for care of unselected patients with undifferentiated problems), 'i lekota onye na ya oria an mbido oria' (Igbo phrase for caring for undifferentiated diseases), 'holistic care', 'Maij waifip' (Comprehensive care in Tangale).

(2) Family with the following examples: 'i tinye uche na ihe gbasara ezi n'ulo' (Igbo phrase for being family focused), 'Ntimzing' (Taroh word for togetherness, oneness or having a family-like nature).

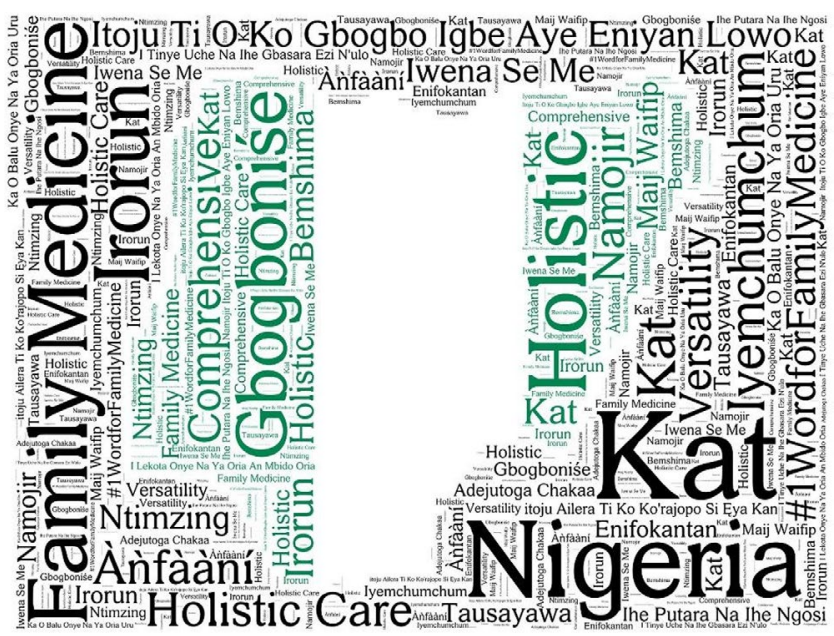

Figure 1: Word cloud image from responses in the form of the Nigerian map and flag.

(3) Skill, values and feelings with the following examples: 'ihe putara n'ihe ñgosi' in Igbo means something that is evidence based, 'i tinye uche na onye na ya oria' (in Igbo means to focus on the patient, i.e. 'patient-centred'), 'tausayawa' (Hausa word for compassion, or sympathy), 'Enifokantan', a Yoruba phrase which means someone you can rely upon.

(4) Professional fulfilment with the following examples: 'Iyemchumchum'..., Taroh word for awesome, 'Iwena se me' Ishan for my work and 'àńfàní', Yoruba for something deeply beneficial/something with lots of opportunities.

The remaining word ('convenience') did not fit recurring patterns of meaning and was not included in any theme.

\section{Discussion}

In response to what they liked most about FM, young Nigerian FPs indirectly described who a FP is and the unique characteristics of the specialty in a country-specific manner. The FP was portrayed as one who possessed a unique skill-set, enjoyed fulfilment in the profession, was familiar with undifferentiated diseases and was thus able to provide holistic care for each patient (irrespective of age and gender), from a family-centred perspective.

The words 'being family focused' and 'having a family-like nature' (examples from the second theme) suggest a philosophy of care arguably different from that of other generalists. This implies that, for each patient encounter, the FP thinks beyond disease determinants that are individual-based to those that arise from or may have been influenced by his/her immediate social unitthe family. By implication, the family may be looked upon as a ready source of support for treatment and ongoing care. This underscores the family not just as the culprit in the diagnosis of the ailment, but as a tool in ensuring the individual receives continuous care in an environment he/she belongs to. This requires skill to achieve as the family structure in many Nigerian settings is hierarchical. ${ }^{16,17}$ Hence, it is not enough for the physician to know the diagnosis; he/she must possess the skill required to gain entrance into an almost exclusive social group, earn their trust and influence their behaviour towards achieving healthy outcomes for the patient in question. 
Table 1: Similarities between themes from the Nigerian study and responses from other countries participating in \#1WordforFamilyMedicine

\begin{tabular}{|c|c|c|c|c|}
\hline Themes from this study & Nigeria (This study) & Portugal $^{14}$ & Argentina $^{13}$ & Italy ${ }^{15}$ \\
\hline \multirow{6}{*}{ Scope } & gbogbonise (all work) & holismo (holism) & multifacética (multifaceted) & olistica (holistic) \\
\hline & kat (all) & todo (all) & englobar (to include) & generale (general) \\
\hline & namojir (all categories of patients) & geral (general) & universal (universal) & comprensiva (inclusive) \\
\hline & maij waifip (comprehensive care) & globalidade (global) & & \\
\hline & & plurifacetada (multifaceted) & & \\
\hline & & cotinuidade (continuity) & & \\
\hline \multirow{3}{*}{ Family } & $\begin{array}{l}\text { ntimzing (togetherness, oneness, } \\
\text { having a family nature) }\end{array}$ & família (family) & unión (union) & famiglia (family) \\
\hline & $\begin{array}{l}\text { i tinye uche na ihe gbasara ezi } \\
\text { n'ulo (family focused) }\end{array}$ & & social (social) & \\
\hline & & & familia (family) & \\
\hline \multirow{8}{*}{ Skill, values \& feeling } & tausayawa (compassion/sympathy) & lealdade (loyalty) & dedicación (dedication) & versatilità (versatility) \\
\hline & $\begin{array}{l}\text { enifokantan (someone you can } \\
\text { rely on) }\end{array}$ & equipa (team) & solidaridad (solidarity) & compassione (compassion) \\
\hline & $\begin{array}{l}\text { ihe putara n'ihe ñgosi (evidence } \\
\text { based) }\end{array}$ & altruísmo (altruism) & compañerismo (companionship) & pazienza (patience) \\
\hline & & colaboração (collaboration) & & alleanza (alliance) \\
\hline & & resiliência (resilience) & & prossimità (proximity) \\
\hline & & dedicação (dedication) & & assistenza (assistance) \\
\hline & & advocacia (advocacy) & & solidarietà (solidarity) \\
\hline & & & & umanità (humanity) \\
\hline \multirow{5}{*}{ Professional fulfilment } & iyemchumchum (awesome) & alegria (joy) & vocación (vocation) & - \\
\hline & iwena se me (my work) & amor (love) & pasión (passion) & \\
\hline & $\begin{array}{l}\text { àńfààní (something deeply } \\
\text { beneficial) }\end{array}$ & devoção (devotion) & & \\
\hline & & realização (fulfilment) & & \\
\hline & & vocação (vocation) & & \\
\hline
\end{tabular}

Though English is the lingua franca of Nigeria, for this study the FPs were asked to respond in their mother tongue. In other countries where the \#1WordforFamilyMedicine project was conducted, e.g. Italy, Argentina, and Portugal, two or more languages were also used to describe what the FPs liked best about family medicine. ${ }^{13-15}$ By utilising one's mother tongue, FPs who were native speakers and could also write in these languages had the unique opportunity to express their feelings with the proper vocabulary, connotation and sentiment. This is the first time creative thinking and insightful analysis using the indigenous languages of the respondents were employed to define the scope of FM within Nigeria. This can be viewed as a strength for this study, especially as similarly themed answers are found in other participating countries, thus reiterating a global perspective. Examples of such similarities are highlighted in Table 1. Yet, translation would have been better performed by specialists in the various languages.

Other areas of strength for this study lie in the exploration of the views of the next generation of FPs. Instead of a top-down approach (based on experts), we used a bottom-up strategy (based on professionals) working within a participatory research paradigm with participants as collaborators. The exploration in this way may have led to findings that more closely reflect reallife FM practice, nowadays and in the near future in Nigeria.

Having observed the above, it is worthy of note that the FPs in this study sample described FM using all of the six competencies as defined by WONCA Europe ${ }^{18}$ save for two: communityoriented care and primary care management. Interestingly, these two competencies have been defined as part of the domains of FM in Nigeria and Africa. ${ }^{5,19,20}$ Perhaps young FPs have seen little of these in their training or practice, hence its absence from their perspective of who an FP is. Assuming these are still part of the FP's training in Nigeria, a separate residency training in community medicine/public health ${ }^{21}$ and the increasing trend in favour of tertiary-based FM training/ practice over community-based centres may have influenced the young FPs (and perhaps the older generation of FPs as well) to relinquish this role, a view which another author seems to share. $^{22}$

In other countries where the \#1WordforFamilyMedicine project was conducted, participants recognised the community aspect of FM. This is reflected in the nomenclature used by many countries in Ibero-America (represented by all Spanish- or Portuguese-speaking countries from Mexico to the southern tip of South America, i.e. Meso-America, South America and the Caribbean) who call themselves 'Family and Community Physicians' rather than simply 'Family Physicians.' Participants from similar (\#1WordforFamilyMedicine) surveys conducted in these countries recognised their role in primary care management. Specific responses from FPs in these countries include 'community oriented', 'cooperation', 'coordination'/'coordinator', 'advocacy'/'advocate,' 'management' and 'gateway'/'gatekeeper.', $13-15$ 
It is possible that different themes/FM characteristics would have emerged had we been able to recruit a more diverse sample with regard to background and ethnicity (we had no response from the south-south region of Nigeria). Perhaps existing electronic mail list for each FM training centre in Nigeria should have been used in addition to the FB platform, emails and text messages by volunteer research assistants. However, we did reach data saturation within our relatively small sample. The current study therefore provides a basis for future, larger, quantitative research in this area especially with regard to the attitudes and competence of Nigerian FPs in providing community-oriented primary care as well as their role in primary care management.

Taken together, our data suggest that FPs in Nigeria focus their activity on providing comprehensive, person-centred care, across time, regardless of the patient's age, sex or health problem. Furthermore, the FP is guided by a particular set of skills and values, and feels professionally accomplished through this way of practising medicine. At variance with previous consensus statements on the domains of FM in Nigeria and Africa, care coordination, primary care management, responsibility for the health of the community and patient empowerment are seemingly left out of the focus of activity of the Nigerian FP. This may suggest a need to expose FM trainees in Nigeria to more primary health care/community-oriented care in a community setting.

Conflict of interest - The authors declare that they have no financial or personal relationship(s) which may have inappropriately influenced them in writing this paper.

\section{ORCID}

K Yakubu (D) http://orcid.org/0000-0002-5385-0143

K Hoedebecke (iD http://orcid.org/0000-0002-3303-2258

L Pinho-Costa (iD) http://orcid.org/0000-0001-9241-4144

Olugbemi Popoola (iD http://orcid.org/0000-0001-6592-6187

Ifeyinwa Okoye (D) http://orcid.org/0000-0003-1309-618X

\section{References}

1. Ajayi AO. The history of the Faculty of General Medical Practice, National Postgraduate Medical College of Nigeria (19802005). A paper delivered at the International Conference to mark the 25th Anniversary of the GMP Faculty; 2005 Nov 3 [cited July 10, 2015]. Available from: http://ifrs-rural.com/ HistoryofFamilyMedicineinNigeria.pdf.

2. Pearson C, Ajayi A, Okunyade M, editors. Training for general medical practice in Nigeria. Proceedings of a conference/workshop which was part of the National Convention of the Association of General Medical Practitioners of Nigeria. Ibadan: Ibadan University Press; 1980 March 27-29.

3. National Postgraduate Medical College of Nigeria. List of accredited training institutions 2015 [cited Dec 11, 2016]. Available from: http:// npmcn.edu.ng/downloads/Accreditationstatusasatdecember2015. pdf.
4. Gray PD. Creation and achievements of the RCGP. In: Lakhani M, editor. A celebration of general practice. Abingdon, United Kingdom: Radcliffe Medical Press; 2003. p. 131-3.

5. Inem AV, Ayankogbe OO, Obazee M, et al. What constitutes the domain of family medicine in West Africa. Nig. Medical Practitioner 2004;45(3):33-7.

6. Monjok E, Okokon IB, Smesny A, et al. Rural health and family medicine: an agenda for sub-Saharan Africa. Afr J Prim Health Care Fam Med. 2011;3(1):271-2.

7. Okokon IB, Ogbonna UK, Asibong UE, et al. Teaching family medicine in medical schools - the perspective from a Nigerian Medical School. Nigerian J Fam Pract. 2012;2(2):1-6.

8. Yakubu K, Hoedebecke K, Nashat N. Young doctor movements: motives for membership among aspiring and young family physicians. J Family Med Prim Care. 2015;4:177-81. https://doi. org/10.4103/2249-4863.154625

9. Hoedebecke $\mathrm{K}$, Pinho-Costa L. \#1WordforFamilyMedicine: Highlighting the role of general practice/family medicine around the world. 2015 [cited 2015 July 9]. Available from: http://bit. ly/1WordforFamilyMedicine.

10. De Bono E. The use of lateral thinking. London: International Center for Creative Thinking; 1967.

11. Hernandez JS, Varkey P. Vertical versus lateral thinking. Physician Exec. 2008;34(3):26-8.

12. Sbaraini A, Carter S, Evans R, et al. How to do a grounded theory study: a worked example of a study of dental practices. BMC Med Res Methodol. 2011;11:182. https://doi.org/10.1186/1471-2288-11-128

13. Hoedebecke K, Suarez A. Representaciones gráicas de amplio significado. Archivos de Medicina Familiar General 2015;12(1):53-4.

14. Hoedebecke $K$, Pinho-Costa L, Mariani Y. Medicina de Familia numa Palavra. Nortemedico 2015;17(1):44. Available from: https://issuu. com/revistanortemedico/docs/nm62_web

15. Hoedebecke K, Celotto S, Demuras J. \#1WordforFamilyMedicine: idee olte le parole. Recenti Prog Med 2015;106(6):291-2.

16. Labeodan MO. The family lifestyle in Nigeria. 2005 [cited 2016 Dec 12]. Available from: http://paa2005.princeton.edu/papers/51248.

17. Wusu O, Isiugo-Abanihe U. Interconnections among changing family structure, childrearing and fertility behaviour among the Ogu, Southwestern Nigeria. 2005 Demographic Res. 2006;14(8):139-56. https://doi.org/10.4054/DemRes.2006.14.8

18. Evans P, ed. Wonca Europe 2011 Edition. The European definition of General Practice/ Family Medicine [cited 2016 Sep 9]. Available from: http://www.woncaeurope.org/sites/default/files/documents/ Definition \%203rd\%20ed\%202011\%20with\%20revised\%20 wonca\%20tree.pdf.

19. Mash R, Reid S. Statement of consensus of family medicine in Africa. 2010;2(1) [cited $2016 \mathrm{Jul}$ 22]. Available from: http://www.phcfm.org/ index.php/phcfm/article/view/151/53.

20. Udonwa N, Ariba A, Yohanna S, et al. Family medicine in West Africa: progress, milestones, and challenges so far in Nigeria (1980-2010). Nigerian J Fam Pract. 2011;1(2):1-9.

21. Asuzu MC. The need, training and assessment of Public Health Medicine Specialists in Nigeria, West Africa. 2007 [cited 2016 Jul 22]. Available from: http://shsph.up.ac.za/papers/PHM2_Asuzu.pdf.

22. Oyedeji R, Abimbola S. How tertiary hospitals can strengthen primary health care in Nigeria. Niger Med J. 2014;55(6):519-20.

Received: 31-08-2016 Accepted: 05-02-2017 


\section{Appendix 1}

\section{Consent form}

Dear Sir/ma'am,

My name is Dr Kenneth Yakubu, a Lecturer with the Department of Family Medicine, University of Jos and a Consultant Family with its affiliate Teaching Hospital Jos University Teaching Hospital. I am also a member of the research theme group of AfriWon Renaissance (the WONCA Young Doctor Movement for Africa).

I will be grateful if you can be part of this brief survey for young family doctors (i.e. $<5$ years post residency training and resident doctors in family medicine) titled: 'A qualitative study of young Nigerian Family Physicians on their profession'. It requires that you provide a single answer or phrase describing what you like most about family medicine. Your identity or address will not be required, just your short response to this question and your affirmation to being a young family doctor as mentioned above.

You are free to decline participation at no consequence. However, if you choose to participate, it will help us understand the collective perspective of young doctors and family medicine residents in our setting.

Kindly tick the appropriate response below stating if you are willing to be part of this study or not.

Following interaction with the researcher:

A. I hereby give consent to be part of this survey

B. I hereby decline participation in this survey

\section{Appendix 2}

\section{Study tool}

1. Kindly tick the status listed below that best describes your current status:

a. Family medicine resident doctor

b. Family physician ( $<5$ years following completion of residency)

2. For the question below, use the language you are most comfortable with (i.e. either English or your mother tongue). Should you choose to write in your mother tongue, kindly write the name of the language in brackets beside your response. Thanks.

Question: Using one word or phrase, kindly describe what you like most about family medicine.

Your response: 